\title{
Joint effect of steel addition and press-and-sinter on the properties of low-cost PM Ti alloys
}

\author{
Leandro Bolzoni ${ }^{1,2, a,{ }^{*}}$, Elisa Maria Ruiz-Navas ${ }^{2, b}$, Elena Gordo ${ }^{2, c}$ \\ ${ }^{1}$ Waikato Centre for Advanced Materials, School of Engineering, The University of Waikato, \\ Private Bag 3105, 3240 Hamilton - New Zealand \\ ${ }^{2}$ Department of Materials Science and Engineering, University Carlos III of Madrid, \\ Avda. de la Universidad, 30, 28911 Leganes, Madrid - Spain \\ aleandro@waikato.ac.nz, bemruiz@ing.uc3m.es, cegordo@uc3m.es
}

\begin{abstract}
Keywords: Low-cost titanium alloys, titanium powder metallurgy, press and sinter, blending elemental, homogeneous microstructure
\end{abstract}

\begin{abstract}
Cheap alloying elements and creative processing techniques are a way forward to open up more industrial opportunities for $\mathrm{Ti}$ in sectors where it is not extensively applied yet, rather than in aerospace and biomedical applications. This study focuses on understanding the joint effect of using a commercial steel powder to add $\mathrm{Fe}$ to pure $\mathrm{Ti}$ and its processing by press-and-sinter on the behaviour of low-cost PM Ti alloys. It is found that the calibrated addition of steel permits to develop new low-cost Fe-bearing Ti alloys that can satisfactorily be produced using the blending elemental PM approach. Densification of the samples and homogenization of the chemical composition are enhanced by the high diffusivity of Fe. The low-cost $\alpha+\beta$ alloys reach comparable physical and mechanical properties to those of wrought-equivalent PM Ti alloys, such as Ti-6Al$4 \mathrm{~V}$, and are therefore promising candidates for load-bearing lightweight products.
\end{abstract}

\section{Introduction}

Light metals are consistently becoming more important structural materials when the weight of the single components or of a whole structure is a relevant engineering aspect, such as in terrestrial vehicles. Lighter vehicles will be more fuel efficient and less polluting contributing toward the reduction of greenhouse gas emissions. Among light metals, Ti has the best combination of properties including the highest mechanical properties in relation to its density, inert behaviour in many different environments (from high-salinity to body fluids) as well as it offers the possibility to tailor its performances via thermomechanical and heat treatment processes [1-3]. The latter is possible thanks to the allotropic phase transformation between the hexagonal close-packed lattice (i.e. $\alpha$-phase) below $882^{\circ} \mathrm{C}$ that transforms into the body-centred-cubic lattice (i.e. $\beta$-phase) above this critical temperature, known as $\beta$ transus $[4,5]$. The alloying elements added to pure Ti can then be categorised depending on their propensity to stabilise or not any of the two phases. In the case of $\beta$ stabilisers they are further divided into isomorphous and eutectoid depending on the nature of their interaction with Ti. In most wrought Ti alloys, $\beta$ eutectoid elements are completely ignored or their content is kept as low as possible with the aim of preventing the formation of brittle intermetallic phases during the melting and solidification of the alloy as per their binary phase diagrams [6]. Fe, that is a eutectoid $\beta$ stabilising element, is not exception and very few wrought alloys such as Ti-1.5Al-5.5Fe-6.8Mo and Ti-5Al-2.5Fe contemplate the use of Fe in their chemical composition [7]. Moreover, high addition of Fe is prevented by its high density as Fe will settle at the bottom of the ingot when cast [5]. Sedimentation of heavier particles can be mitigated by mixing prior to processing and the formation of brittle intermetallic phases can be managed due to the slower kinetics of reaction in the solid state if Ti alloys are produced using PM (powder metallurgy). Actually, the use of ingenious techniques such as PM, rather than the conventional metallurgical wrought route, and the employment of cheaper alloying elements have been identified as the two critical aspects for the development and fabrication of more affordable Ti-based components [8]. 
Regarding PM methods, they are especially advantageous for $\mathrm{Ti}$ as the affinity of $\mathrm{Ti}$ for interstitials and its reactivity increase with the temperature and, normally, lower processing temperature are used in PM with respect to wrought metallurgy as in the former the material never reaches the molten state. Moreover, the need of machining operations is limited in the case of PM products and this has multiple benefits as $\mathrm{Ti}$ is a difficult-to-machine metal due to its low conductivity and $\mathrm{Ti}$ is an expensive material so are its swarf.

In recent years the addition of Fe to Ti using powder metallurgy method is starting to attract more attention. For example, Chen et al. [9] studied the production of binary Ti-xFe (x = 3-7 wt.\%) by blending carbonyl Fe powder with gas atomised $\mathrm{Ti}$ and processing them via cold compaction and vacuum sintering $\left(1150^{\circ} \mathrm{C}-2 \mathrm{~h}\right)$. They obtained relative density values around $95 \%$, and found that hardness and tensile strength increase but elongation decreases with the amount of Fe. Savvakin et al. [10] evaluated the effect of Fe content on the sinterability of two blended elemental Ti-V-Fe-Al alloys cold pressed compacts sintered at $1250^{\circ} \mathrm{C}$ up to $4 \mathrm{~h}$ where Fe was added using a purposely produced Fe-containing master alloys. They mainly concluded that increasing the Fe content improves the densification but also causes some grain coarsening.

This work deals with the production and characterisation of low-cost Fe-bearing PM Ti alloys. Cost reduction of the material derives from different aspects: the choice of the alloying elements (i.e. cheaper $\beta$-stabilisers with respect to commonly used elements such as $\mathrm{V}$, $\mathrm{Zr}$ or Mo), the use of commercially and readily available powders, and the manufacturing method selected. In particular steel is used as medium to add Fe to pure Ti and the blended elemental alloys are shaped into parts using the cheapest PM techniques available for Ti, cold uniaxial press and sintering under vacuum.

\section{Experimental Procedure}

A hydride-dehydride (HDH) pure Ti powder with particle size lower than $90 \mu \mathrm{m}$ and purity $>99.8 \%$ (as per supplier specification, GfE GmbH) was chosen as base material. Fe was selected as primary $\beta$-stabilising element and its addition was done via the use of a commercial 4140 low-alloy steel powder obtained via gas atomisation and with particle size lower than $27 \mu \mathrm{m}$ (Sandvik Ltd.). The actual chemical composition of the 4140 low-alloy steel powder contemplates minor additions (i.e. $<1$ wt.\%) of other elements such as Cr, Mn and Mo and their effect was taken into account during the design of the low-cost Fe-bearing PM Ti alloys. From literature, the optimum Fe addition for low-cost PM Ti alloys is in the range between 5 wt.\% to 7 wt.\% [11]. The corresponding $\beta$ stabilising strength of these $\mathrm{Fe}$ additions is, respectively, $12.5 \%$ and $17.5 \%$ of Equivalent Molybdenum Content, as per Molchanova relationship [12]. These values were then used to calculate the correct corresponding additions of 4140 low-alloy steel powder.

The alloys were labelled as Ti-5.1S and Ti-7.1S and produced by mixing the pure Ti and steel powders in a Turbula mixer during 30 minutes. Particles size distribution by laser diffraction, oxygen and nitrogen contents via inert fusion gas technique and analysis of the morphology of the powder were the properties of the starting powders quantified. Cold compaction of the samples was performed in a uniaxial hydraulic press applying $700 \mathrm{MPa}$. The wall of the die were lubricated with zinc strearate as to reduce friction during ejection of the samples without considerably contaminating the powder in order to prevent the pickup of interstitial elements. Pressed samples were laid on $\mathrm{ZrO}_{2}$ pearls contained into an $\mathrm{Al}_{2} \mathrm{O}_{3}$ tray for high vacuum sintering. For this last the dwell time (1h), the heating and cooling rates (i.e. $5^{\circ} \mathrm{C} / \mathrm{min}$ ) and the vacuum level of $10^{-5}$ mbar were kept constant. The sintering temperatures selected were: $900^{\circ} \mathrm{C}, 1200^{\circ} \mathrm{C}$ and $1300^{\circ} \mathrm{C}$.

Microstructure analysis, physical properties like density (via Archimedes' buoyancy principle) and porosity and Vickers hardness measurements were the characterisations conducted on the sintered samples. For microstructural analysis the samples were prepared by following the classical metallographic preparation ( $\mathrm{SiC}$ papers grinding plus $\mathrm{SiO}_{2}$ gel polishing) and etched by means of Kroll reactant as to reveal the microconstituents. Optical micrographs were taken using an Olympus GX71 microscope. 


\section{Results and Discussion}

Characterisation of the staring powders

Table 1 shows some basic properties of the starting low-cost Fe-bearing Ti-5.1S and Ti-7.1S powders. Their theoretical density was calculated using the rule of mixtures, and it is somewhat higher with respect to that of pure Ti (i.e. $4510 \mathrm{~kg} / \mathrm{m}^{3}$ ) [13] mainly due to the presence of Fe, the major alloying element. Correspondingly the density of the alloys increases with the total amount of steel powder added to pure Ti. The Ti-5.1S and Ti-7.1S starting powders are characterised by a Gaussian particle side distribution with a mean size of approximately $47 \mu \mathrm{m}$ and maximum size lower than 170 mesh or $88 \mu \mathrm{m}$ mainly due to the HDH pure Ti powder. The interstitials contents are slightly higher than the limit specified for the most common $\alpha+\beta$ Ti alloy, the Ti-6Al-4V alloy $(0.20$ wt.\% and 0.05 wt.\% for oxygen and nitrogen, respectively) [13].

Table 1. Basic properties of the low-cost Fe-bearing PM Ti powders studied.

\begin{tabular}{|c|c|c|c|c|c|}
\hline \multirow{3}{*}{ Alloy } & \multicolumn{5}{|c|}{ Property } \\
\cline { 2 - 6 } & \multirow{2}{*}{ Theoretical density $\left[\mathrm{kg} / \mathrm{m}^{3}\right]$} & \multicolumn{2}{|c|}{ Particle size $[\mu \mathrm{m}]$} & \multicolumn{2}{c|}{ Interstitials [wt.\%] } \\
\cline { 3 - 6 } & & $D_{50}$ & $D_{M A X}$ & $O$ & $N$ \\
\hline \hline Ti-5.1S & 4680 & 46.52 & $<88$ & 0.24 & 0.056 \\
\hline Ti-7.1S & 4750 & 47.14 & $<88$ & 0.22 & 0.058 \\
\hline
\end{tabular}

The morphology of the raw materials, (i.e. HDH pure Ti and 4140 low-alloy steel powders) was characterised via SEM analysis and representative micrographs are shown in Figure 1. On the one side, the irregular morphology of the HDH pure Ti powders is consistent with the comminution process used to produce it and it is ideal for the chosen process as the interparticle looking generated during uniaxial pressing will form the backbone of the green samples and provide the strength needed for the handling of the samples. On the other side, the 4140 low-alloy steel powder has primarily a spherical morphology, because obtained by gas atomisation, but some elongated and particles with satellites are also observed. The much finer particle size of the steel powder should allow the particles to sit in between the structure formed by the Ti powder particles, leading to a somewhat higher green density in comparison to pure Ti. Moreover, fine particles are expected to promote the densification of the material, as per surface area reduction driving force, and the homogenisation of the chemical composition, due to the high diffusivity of Fe in $\mathrm{Ti}[14,15]$.
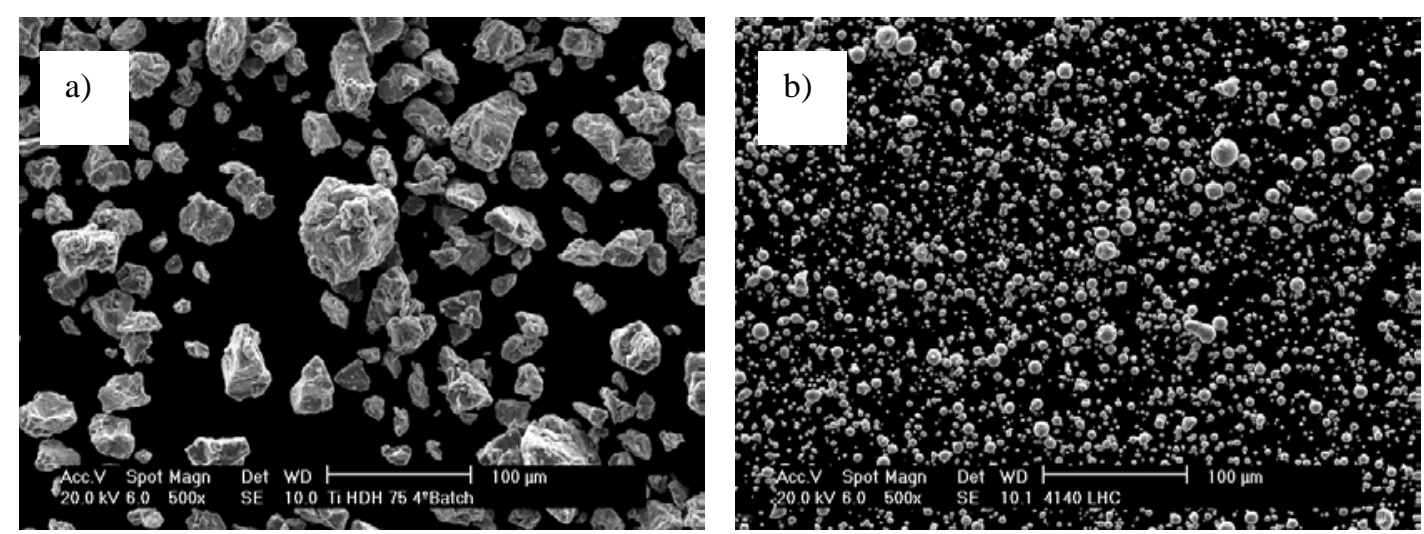

Figure 1. Secondary electron micrographs of the raw materials: a) HDH pure Ti powder and b) 4140 low-alloy steel powder.

The compacted Ti-5.1S and Ti-7.1S alloys have a green density of $79.6 \pm 0.4 \%$ and $80.4 \pm 0.3 \%$, respectively. The total amount of steel powder added affects the packing and deformation of the particles resulting in a somewhat higher green density for the Ti-7.1S alloy after uniaxial pressing. 
Once pressed the samples could easily be ejected and showed complete integrity and no signs of delamination/fracture. Regardless of the processing temperature employed, the sintering of the Ti-5.1S and Ti-7.1S alloys induces their shrinkage and therefore the reduction of the dimensions of the samples. From Figure 2, the shrinkage is quite homogeneous along the three dimensions at the low sintering temperature of $900^{\circ} \mathrm{C}$ but at higher temperatures the length and width shrinkages are, on average, 1.5 times greater than along the thickness of the specimens. This behaviour applies to both alloys and it is thus related to the geometry and pressing of the samples rather than the intrinsic composition of the alloy has the Ti-5.1S and Ti-7.1S alloys have very similar shrinkage values (most within their variability), with a mean difference of $0.2 \%$. It can also be noticed that the shrinkage of the samples is related to the sintering temperature, the higher the temperature the higher the shrinkage. Consequently, in this study the highest change in shrinkage values happens when the sintering temperature is risen from $900^{\circ} \mathrm{C}$ to $1200^{\circ} \mathrm{C}$.

The results of the microstructural analysis are reported in Figure 3 where it can be seen that the Ti5.1S and Ti-7.1S alloys are characterised by the typical microstructure of $\alpha+\beta$ Ti alloys slow cooled from a manufacturing temperature higher than the $\beta$ transus of the alloy [16, 17]. It is worth mentioning that the micrographs of the samples sintered at $900^{\circ} \mathrm{C}$ are not shown as this low sintering temperature did not permitted to reach a full homogeneous distribution of the alloying elements as some very small undissolved steel particles could still be found. Nevertheless, most of the alloying elements, especially Fe diffused substantially and a fair amount of stabilised $\beta$ phase was also present. Furthermore, as most of the thermal energy supplied was primarily used in diffusion for homogenisation, in agreement with the shrinkage data of Figure 2, the densification of the samples was quite limited. Thus, the residual porosity was still mainly irregular in shape and highly interconnected and some particle size boundary were still present. For the samples sintered in the $1200-1300^{\circ} \mathrm{C}$ window the diffusion of the alloying elements is complete and the microstructure fully homogeneous in terms of chemical composition. The microconstituents of the low-cost Febearing PM Ti-5.1S and Ti-7.1S alloys are $\alpha$ grains located at the grain boundaries, as they nucleated and grew upon cooling from the prior $\beta$, and $\alpha+\beta$ lamellae sharing the same orientation relationship within the same $\alpha$ grain but with different orientation among the different $\alpha$ grains. The residual porosity present in the specimens sintered at $1200^{\circ} \mathrm{C}$ or $1300^{\circ} \mathrm{C}$ has spherical morphology, the pores are not interconnected anymore and it is primarily closed porosity and thus the relative density should be greater than 92-94\% [18]. No remarkable differences can be seen when comparing the microstructure of the Ti-5.1S and Ti-7.1S alloys if not the higher amount of $\beta$ phase and the coarser nature of the microconstituents of the Ti-7.1S alloy; the interlamellar spacing is supposed to be reduced for a higher addition of $\mathrm{Fe}$ as indicated by Chen et al [9]. The microstructural analysis also permitted to verify that the expected formation of brittle Fe-based intermetallic phases did not occur as no such phases were found as microconstituent of the alloys. 

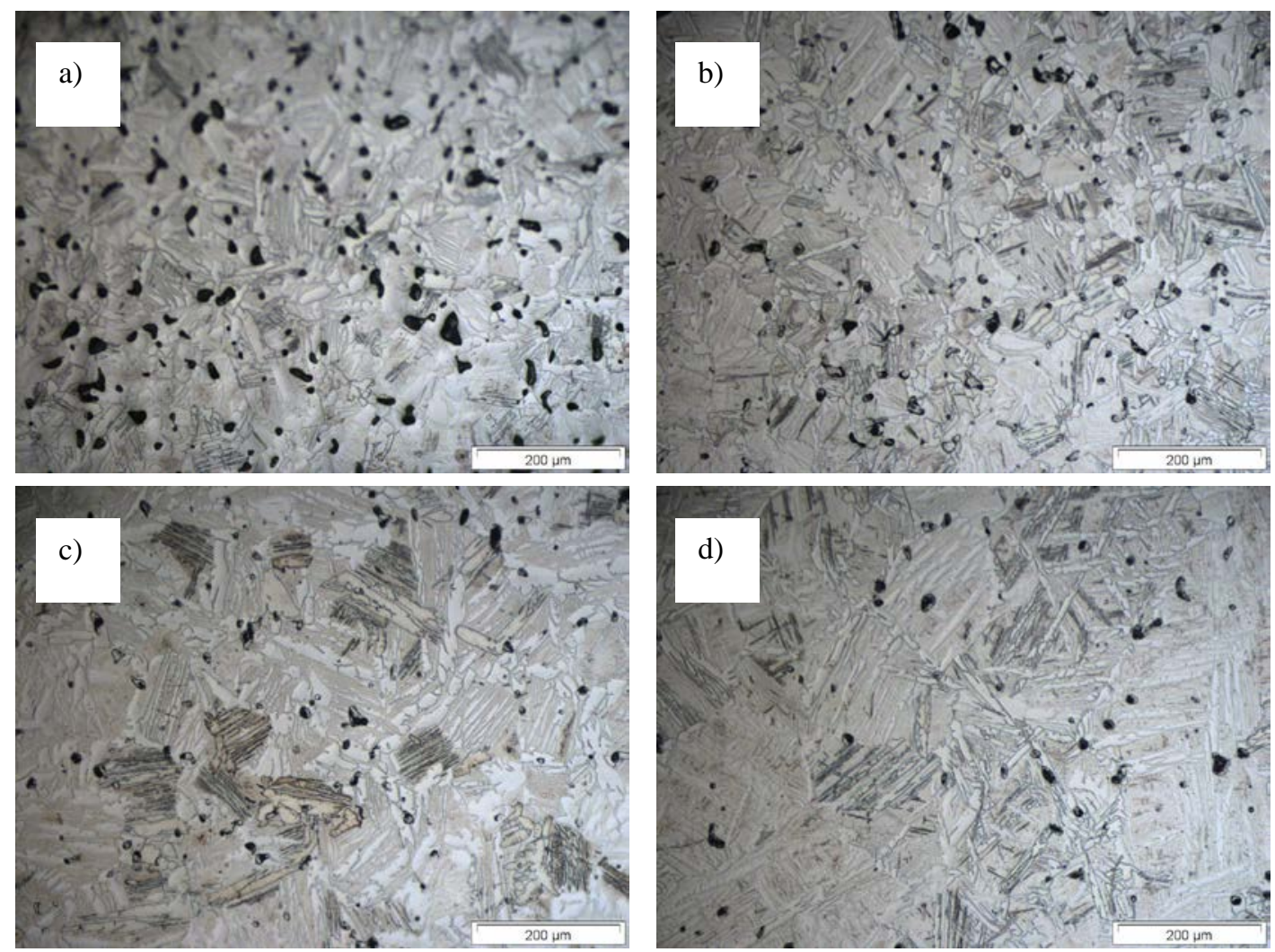

Figure 3. Optical micrographs for the Ti-5.1S (left) and Ti-7.1S (right) alloys, respectively, sintered at: a) and b) $1200^{\circ} \mathrm{C}$ and c) and d) $1300^{\circ} \mathrm{C}$.

The nature of the phases composing the sintered Ti-5.1S and Ti-7.1S alloys (i.e. $\alpha$-Ti and $\beta$-Ti phases) was also confirmed via XRD analysis (not shown for brevity).

The microstructural analysis results indicated that the total residual porosity of the low-cost Febearing PM Ti-5.1S and Ti-7.1S alloys decreases, or in turns the relative density increases, with the increment of the processing temperature. From the data of the density and porosity shown in Figure 4 , it seems that there is a proportionality between the sintering temperature and the physical properties of the alloys. Thus, not only the density increases and the porosity decreases with the temperature but, in this study, the higher change is consequently experienced when raising the temperature from $900^{\circ} \mathrm{C}$ to $1200^{\circ} \mathrm{C}$. The behaviour described is consistent with the classical sintering theory and confirms that the sintering temperature of $900^{\circ} \mathrm{C}$ is not sufficiently high as to induce the full homogenisation of the alloying elements and to form a network of close porosity. This suggests that the material does not reach the final stage of sintering as in the case for the samples sintered at $1200^{\circ} \mathrm{C}$ and $1300^{\circ} \mathrm{C}$. This behaviour is the direct consequence of the thermodynamics of the system and the relative low diffusivity at $900^{\circ} \mathrm{C}$, temperature that is expected to be lower than the $\beta$ transus of the low-cost Fe-bearing alloys studied. Density data show that the Ti-7.1S alloy has higher density than the Ti-5.1S alloy. However, this is primarily due to the greater amount of alloying contemplated in the alloy composition, whose density is higher than that of $\mathrm{Ti}$, as the porosity data reveal that the two alloys have comparable residual porosity with possibly the exception of the alloys sintered at $1300^{\circ} \mathrm{C}$. The porosity level achieved and the equivalent relative density values are common values for PM Ti alloys made using the blending elemental approach [5, 9, 16, 17, 19, 20].

Consistently with the data plotted in Figure 4, the hardness of the low-cost Fe-bearing PM Ti5.1S and Ti-7.1S alloys increases with the sintering temperature as the residual porosity is reduced and the composition of the material becomes more homogeneous. Once again, the highest change happen with the highest increment in sintering temperature. It is worth mentioning that the sintered low-cost alloys have comparable interstitials contents of approximately $0.50 \mathrm{wt} . \%$ oxygen and 0.07 wt.\% nitrogen irrespectively of the alloying composition or the processing temperature. Therefore, it 
can be noticed that there is a remarkable effect from the total content of alloying elements as the Ti-5.1S alloy has always lower hardness with respect to the Ti-7.1S alloy. The hardness values of the materials developed are similar to those of other Ti-based alloys made via PM [11, 16, 17]. Despite of the presence of the residual porosity, the sintered low-cost $\mathrm{Ti}$ alloys also have similar hardness to the Ti-6Al-4V alloy obtained using the conventional metallurgical route due to the lower interstitials contents of the wrought alloy.

\section{Conclusions}

In this study the joint effect of using a fine spherical steel powder to add Fe to pure Ti and the processing of the designed alloying via the pressand-sinter powder metallurgy route was evaluated. It is found that the low-cost Fe-bearing alloys can successfully be shaped into handable products without any fracture or delamination. The use of fine alloying elements powder is beneficial to promote the diffusion of the elements, the homogenisation of the chemical composition and the densification of the material. However, when a sintering temperature below the $\beta$ transus combined with a relatively short time of $1 \mathrm{~h}$ is employed, the material is not fully homogeneous. The developed low-cost alloys are characterised by the typical microstructure of $\alpha+\beta$ Ti alloy slow cooled from high temperature and the microconstituents are coarser for higher additions of Fe. When using conventional sintering temperature for $\mathrm{Ti}$ alloys (i.e. $1200-1300^{\circ} \mathrm{C}$ ), the porosity and relative density of the alloys are comparable to those of other wrought-equivalent and/or powder metallurgy Ti alloys. Consequently, the hardness of the low-cost alloys is also of the same magnitude of the previously mentioned materials and it is, in most of the cases, higher with respect to the wrought Ti-6Al-4V alloy due to the higher interstitials contents.

\section{Acknowledgments}

The financial support from New Zealand Ministry of Business, Innovation and Employment (MBIE) through the TiTeNZ project (UOWX1402 research contract) is sincerely acknowledged.

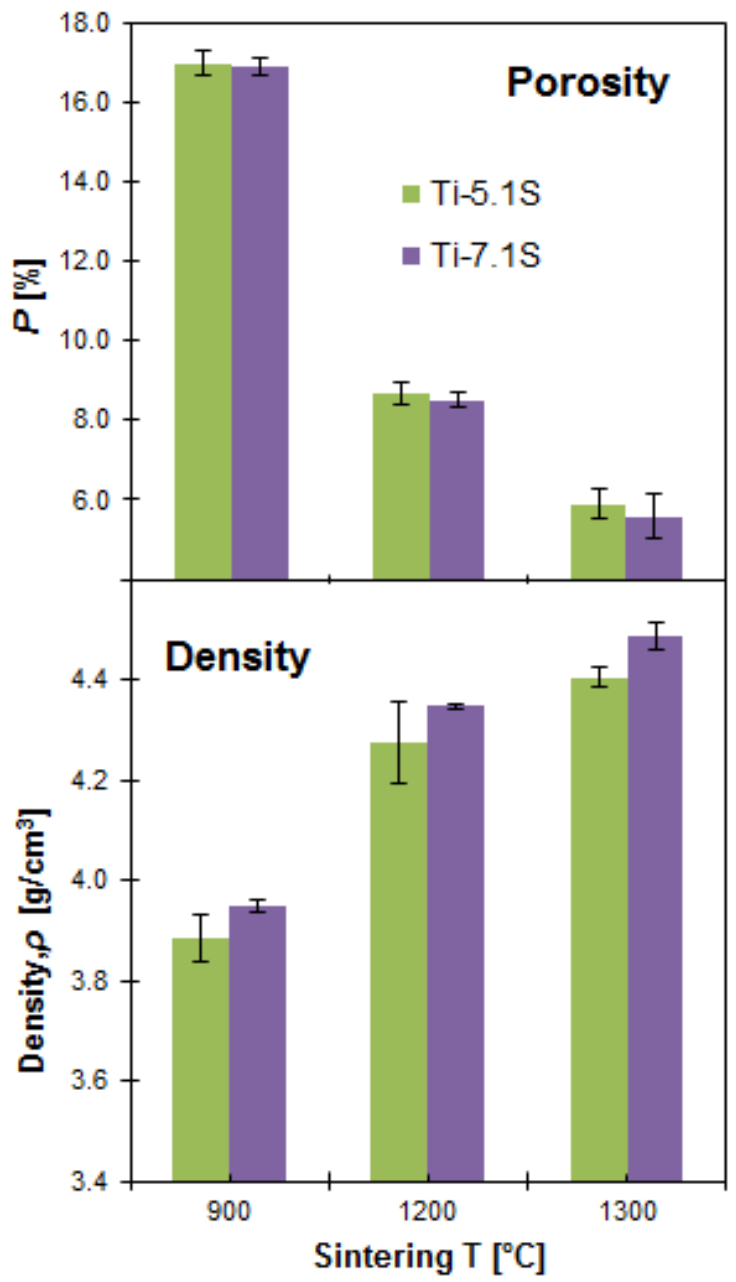

Figure 4. Residual porosity and density versus sintering temperature for the Ti-5.1S and Ti-7.1S alloys.

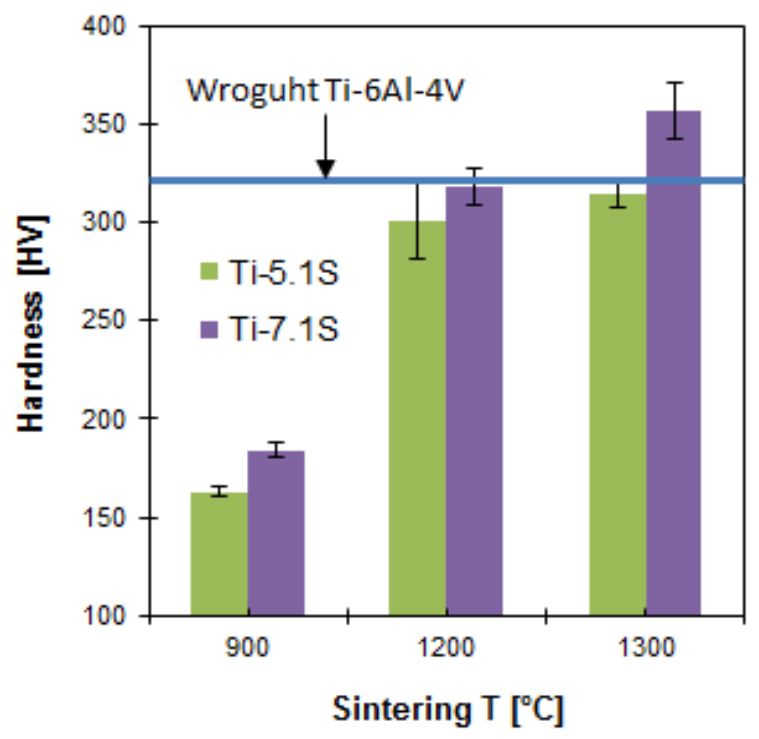

Figure 5. Vickers hardness versus sintering temperature for the Ti-5.1S and Ti-7.1S alloys. 


\section{References}

[1]Polmear IJ, Light Alloys. From Traditional Alloys to Nanocrystals. $4^{\text {th }}$ ed., 2006: ButterworthHeinemann, UK.

[2] Leyens C, Peters M, Titanium and Titanium Alloys. Fundamentals and Applications, 2003, Köln, Germany: Wiley-VCH.

[3] Joshi VA, Titanium Alloys: An Atlas of Structures and Fracture Features. 2006: Taylor \& Francis.

[4] Jaffee RI, The Physical Metallurgy of Titanium Alloys. Progress in Metal Physics, 1958. 7: p. 65-163.

[5] Bolzoni L, Ruiz-Navas EM, Gordo E, Powder Metallurgy CP-Ti Performances: Hydridedehydride vs. sponge. Materials and Design, 2014. 60: p. 226-232.

[6] Murray JL, Phase Diagrams of Binary Titanium Alloys. 1st ed. Monograph Series on Alloy Phase Diagrams. 1987: ASM International.

[7] Lütjering G, Williams JC, Titanium: Engineering Materials and Processes. $1^{\text {st }}$ ed., 2003, Manchester, UK: Springer.

[8] Froes FH, Gungor MN, Imam MA, Cost-affordable Titanium: The Component Fabrication Perspective. JOM, 2007. 59(6): p. 28-31.

[9] Chen B-Y, Hwang K-S, Ng K-L, Effect of Cooling Process on the $\alpha$ Phase Formation and Mechanical Properties of Sintered Ti-Fe Alloys. Materials Science and Engineering: A, 2011. 528(13-14): p. 4556-4563.

[10] Savvakin DG et al., Effect of Iron Content on Sintering Behavior of Ti-V-Fe-Al Near- $\beta$ Titanium Alloy. Metallurgical and Materials Transactions A, 2012. 43(2): p. 716-723.

[11] Bolzoni L et al., Study of the Properties of Low-cost Powder Metallurgy Titanium Alloys by 430 Stainless Steel Addition. Materials and Design, 2014. 60: p. 628-636.

[12] Molchanova K, Phase Diagrams of Titanium Alloys. Translation of Atlas Diagram Sostoyaniya Titanovyk Splavov), Israel Program for Scientific Translations, Jerusalem, 1965: p. 154.

[13] Boyer R, Welsch G, Collings EW, Materials Properties Handbook: Titanium Alloys. ASM International. 1998: Ohio, USA.

[14] Nakajima H, Yusa K, Kondo Y, Diffusion of Iron in a Diluted [Alpha]-Ti-Fe Alloy. Scripta Materialia, 1996. 34(2): p. 249-253.

[15] Nakajima H, Ohshida S, Nonaka K, et al., Diffusion of Iron in [Beta] Ti-Fe Alloys. Scripta Materialia, 1996. 34(6): p. 949-953.

[16] Bolzoni L et al., Mechanical Behaviour of Pressed and Sintered CP Ti and Ti-6Al-7Nb Alloy Obtained from Master Alloy Addition Powder. Journal of the Mechanical Behavior of Biomedical Materials, 2013. 20: p. 149-161.

[17] Bolzoni L, Ruiz-Navas EM, Gordo E, Feasibility Study of the Production of Biomedical Ti6Al-4V Alloy by Powder Metallurgy. Materials Science and Engineering C, 2015. 49: p. 400-407.

[18] German RM, Powder Metallurgy Science. $2^{\text {nd }}$ ed., 1994, Princeton, USA: MPIF - Metal Powder Industries Federation.

[19] Ivasishin OM, Cost-effective Manufacturing of Titanium Parts with Powder Metallurgy Approach. Materials Forum 2005. 29: p. 1-8.

[20] Froes FH et al. Cost-effective Synthesis of Ti-6Al-4V Alloy Components via the Blended Elemental P/M Approach. Symposium on TMS Symposium on High Performance Metallic Materials for Cost Sensitive Applications. 2002. Seattle, WA. 